\title{
Puerarin induces cell apoptosis in human chondrosarcoma cell line SW1353 via inhibition of the PI3K/Akt signaling pathway
}

\author{
LI HUANG $^{1}$, JUNQING CAO $^{2}, \mathrm{LAN} \mathrm{CAO}^{2}, \mathrm{LING} \mathrm{GAO}^{3}, \mathrm{YING} \mathrm{YANG}^{2}$ and $\mathrm{LI} \mathrm{XU}^{2}$ \\ Departments of ${ }^{1}$ Gastrointestinal, ${ }^{2}$ Spine and ${ }^{3}$ General Surgery, Wuhan Integrated TCM and \\ Western Medicine Hospital (Wuhan No. 1 Hospital), Wuhan, Hubei 430022, P.R. China
}

Received March 30, 2016; Accepted June 9, 2017

DOI: $10.3892 / 01.2017 .6901$

\begin{abstract}
Chondrosarcoma is a malignant soft tissue sarcoma with poor prognosis. Puerarin has been demonstrated to possess anticancer properties; however, the effects of puerarin in human chondrosarcoma cells remain unknown. The present study aimed to investigate the anticancer effects of puerarin in SW1353 human chondrosarcoma cells. SW1353 cells were treated with increasing concentrations of puerarin for different durations. Cell viability was evaluated using MTT assays. Cell apoptosis rates were determined by flow cytometry. The activities of caspase- 3 and caspase- 9 were measured by enzymatic assay. The expression of RAC-alpha serine/threonine-protein kinase (Akt), phosphorylated-Akt, caspase-3 and apoptosis-associated proteins, including B-cell lymphoma 2 (Bcl-2) and Bcl-2-associated X protein (Bax) were detected by western blotting. Puerarin significantly decreased cell viability and significantly induced apoptosis of SW1353 cells. In addition, puerarin significantly increased the enzymatic activities of caspase-3 and caspase-9. Puerarin treatment suppressed the expression of p-Akt and Bcl-2 but promoted the expression of Bax and cleaved caspase- 3 in SW1353 cells. Notably, the phosphatidylinositol 3-kinase (PI3K) inhibitor LY294002 abrogated the decreased phosphorylation of Akt, suggesting that the PI3K/Akt signaling pathway is involved in mediating the anticancer effects of puerarin. The data from the present study indicated that puerarin exhibits anticancer effects in SW1353 cells and may be a potential therapeutic drug for patients with chondrosarcoma.
\end{abstract}

\section{Introduction}

Chondrosarcoma is a malignant soft tissue sarcoma with poor prognosis, and it is the second most common primary

Correspondence to: $\mathrm{Dr} \mathrm{Li} \mathrm{Xu}$, Department of Spine, Wuhan Integrated TCM and Western Medicine Hospital (Wuhan No. 1 Hospital), 215 Zhongshan Avenue, Wuhan, Hubei 430022, P.R. China

E-mail: lixu1978@outlook.com

Key words: puerarin, chondrosarcoma, SW1353 cells, apoptosis, $\mathrm{PI} 3 \mathrm{~K} / \mathrm{Akt}$ signaling pathway bone tumor among all malignant bone tumors (1). At present, surgical resection remains the primary treatment option for chondrosarcoma (2). Due to its poor response to conventional chemotherapy and radiation therapy, chondrosarcoma is challenging to manage (3). Therefore, novel and effective therapeutic approaches are required for patients with chondrosarcoma.

Puerarin, the major active ingredient extracted from Radix puerariae, exhibits beneficial effects for cardiovascular diseases, neurological dysfunction, diabetes, osteoporosis, liver injury and inflammation (4). Previous studies have indicated that puerarin exhibits anticancer effects and induces tumor cell apoptosis in a number of cancer cell types, including colon cancer HT-29 cells, human mantle Z138 cells, human glioblastoma cells, stomach cancer cells and breast cancer cells (5-9). Furthermore, increasing evidence has indicated the mechanisms involved in the biological effect of puerarin. In hFBO1.19 cells, puerarin attenuated the dexamethasone (DEX)-induced release of cytochrome $c$ and cleavage of caspase-3, which was associated with inhibition of the c-Jun N-terminal kinase (JNK) pathway and activation of the phosphoinositide 3-kinase (PI3K)/threonine-protein kinase (Akt) signaling pathway (10). Puerarin increases proliferation and differentiation and opposes cisplatin-induced apoptosis in human osteoblastic MG-63 cells. At least partially, puerarin functions via activation of MEK/extraellular signal-regulated kinase and PI3K/Akt signaling pathways (11). However, the effects of puerarin on the human chondrosarcoma cell line SW1353 and the molecular mechanisms underlying these effects remain unclear.

In the present study, puerarin decreased cell viability and induced apoptosis in SW1353 cells via inhibition of the P13K/RAC-alpha serine/Akt signaling pathway. These results elucidated the potential molecular mechanisms underlying the anticancer effect of puerarin in SW1353 cells, which may provide an insight into novel therapeutic options for patients with chondrosarcoma.

\section{Materials and methods}

Materials. The human chondrosarcoma cell line SW1353 was purchased from the Cell Bank of Type Culture Collection of Chinese Academy of Sciences (Shanghai, China). Puerarin, LY294002, PD98059, SP600125 and SB203580 were purchased from Sigma-Aldrich (Merk KGaA, Darmstadt, Germany). Rabbit anti-human antibodies against Bax (cat no. 2774), Bcl-2 
(cat no. 2872), Caspase-3 (cat no. 9664), Akt (cat no. 9272), p-Akt (Ser473; cat no. 9271) and GAPDH (cat no. 2118) were obtained from Cell Signaling Technology, Inc. (Danvers, MA, USA).

Cell culture. SW1353 cells were cultured in L-15 medium (Hyclone; GE Healthcare Life Sciences Logan, UT, USA) supplemented with $10 \%$ fetal bovine serum (Gibco; Thermo Fisher Scientific, Inc., Waltham, MA, USA) and incubated at $37^{\circ} \mathrm{C}$ in a humidified atmosphere of $5 \% \mathrm{CO}_{2}$.

MTT assay. SW1353 cells $\left(1 \times 10^{4}\right.$ cells/well) were treated with puerarin in 96-well plates (Costar; Corning Incorporated, Corning, NY, USA) for $48 \mathrm{~h}$. Then, cultures were washed with PBS. MTT (Sigma-Aldrich; Merk KGaA) was added to each well and the mixture was incubated at $37^{\circ} \mathrm{C}$ for $2 \mathrm{~h}$. To dissolve the formazan crystals, culture medium was then replaced with an equal volume of dimethyl sulphoxide (Merck $\mathrm{KGaA}$ ). Following agitation at room temperature for $10 \mathrm{~min}$, the absorbance of each well was determined at $570 \mathrm{~nm}$ using a microplate reader (Bio-Tek Instruments, Inc., Winooski, VT, USA). The inhibitory rate $(\%)=\left(\right.$ optical density $(\mathrm{OD})_{\text {control }}$ group $\left.-\mathrm{OD}_{\text {test group }}\right) \times 100 \% / \mathrm{OD}_{\text {control group. }}$.

Cell apoptosis by flow cytometry analysis. Apoptotic cells were measured with the Annexin V/fluorescein isothiocyanate (FITC) kit (BD Biosciences, Franklin Lakes, NJ, USA) according to the manufacturer's protocol. Briefly, $1 \times 10^{6}$ cells were collected, washed three times with PBS and were resuspended in $300 \mu \mathrm{l}$ of binding buffer. A total of $5 \mu \mathrm{l}$ of Annexin V-FITC solution and $5 \mu \mathrm{l}$ of propidium iodide (PI) were added and incubated in the dark at $37^{\circ} \mathrm{C}$ for $15 \mathrm{~min}$. Then, the cytofluorimetric analyses were performed on a BD FACSVerse (BD Biosciences) and data were analyzed using FACSuite software version 1.0 (BD Biosciences).

Enzymatic assay for caspase-3 and caspase-9 activity. Caspase activity was detected using caspase-3 and caspase-9 activity assay kits (Beyotime Institute of Biotechnology, Haimen, China) according to the manufacturer's protocol. Cells were lysed and total cellular protein extracts were quantified using a Protein-assay kit (Bio-Rad Laboratories, Inc., Hercules, CA, USA). An equal amount of total protein extract was incubated at $37^{\circ} \mathrm{C}$ overnight with either Ac-DEVD-pNA for the caspase-3 assay or Ac-LEHD-pNA for the caspase-9 assay. The release of pNA was estimated by determining the absorbance at $405 \mathrm{~nm}$ on a microplate ELISA reader (Bio-Rad Laboratories, Inc.). Results are presented with the fold change in activity compared with the untreated control.

Western blot analysis. Cells were collected, washed and lysed with radioimmunoprecipitation assay buffer, including $50 \mathrm{mM}$ Tris- $\mathrm{HCl}(\mathrm{pH}=7.4), 150 \mathrm{mM} \mathrm{NaCl}, 1 \%$ Nonidet P-40, $0.25 \% \mathrm{NaN}_{3}, 1 \mathrm{mM}$ EDTA, $1 \mathrm{mM}$ PMSF, $1 \mu \mathrm{g} / \mathrm{ml}$ aprotinin, $1 \mu \mathrm{g} / \mathrm{ml}$ leupeptin, $1 \mu \mathrm{g} / \mathrm{ml}$ pepstatin $\mathrm{A}, 1 \mathrm{mM}$ sodium orthovanadate and $1 \mathrm{mM} \mathrm{NaF}$. Then, the protein concentration was determined using a BCA Protein Assay kit (Thermo Fisher Scientific, Inc.). The proteins $(20 \mu \mathrm{g})$ were resolved on a $10 \%$ SDS-PAGE gel and transferred to polyvinylidene fluoride membranes. The blots were blocked with 5\% BSA (Sigma-Aldrich; Merck KGaA) for $1 \mathrm{~h}$ at room temperature,
Table I. Inhibitory rate of puerarin on the proliferation of cells.

\begin{tabular}{lcc}
\hline $\begin{array}{l}\text { Puerarin } \\
(\mu \mathrm{M})\end{array}$ & $\begin{array}{c}\text { Optical density }(570 \mathrm{~nm}) \\
(\text { mean } \pm \text { standard deviation) }\end{array}$ & $\begin{array}{c}\text { Inhibitory } \\
\text { rate }(\%)\end{array}$ \\
\hline 0 & $0.995 \pm 0.004$ & 0 \\
50 & $0.886 \pm 0.012$ & $10.254 \pm 0.671$ \\
100 & $0.724 \pm 0.013$ & $26.536 \pm 0.582$ \\
150 & $0.618 \pm 0.018$ & $37.089 \pm 0.622$ \\
200 & $0.475 \pm 0.014$ & $51.461 \pm 0.706$ \\
250 & $0.362 \pm 0.016$ & $62.718 \pm 0.654$ \\
300 & $0.254 \pm 0.012$ & $73.672 \pm 0.636$ \\
\hline
\end{tabular}

and probed with rabbit anti-human antibodies against Bax, Bcl-2, Caspas-3, Akt, p-Akt (Ser473) or GAPDH (1:1,000 dilution) for $1 \mathrm{~h}$ at room temperature. After washing three times with PBS, the blots were incubated with a horseradish peroxidase-conjugated donkey anti-rabbit secondary antibody (1:1,000 dilution; cat no. sc2313; Santa Cruz Biotechnology, Inc., Santa Cruz, CA, USA) for $1 \mathrm{~h}$ at room temperature. The signals were visualized by enhanced chemiluminescence (Pierce; Thermo Fisher Scientific, Inc.). Images were captured using a scanner (GE Healthcare, Chicago, IL, USA) and proteins were quantified using Image $\mathrm{J}$ software version 1.42 (National Institutes of Health, Bethesda, MD, USA).

Statistical analysis. Data were analyzed using SPSS statistical software version 13.0 (SPSS, Inc., Chicago, IL, USA) and the data were reported as the mean \pm standard deviation. Statistical analysis between two samples was evaluated using a Student's t-test. $\mathrm{P}<0.05$ was considered to indicate a statistically significant difference.

\section{Results}

Puerarin inhibits the viability of human chondrosarcoma SW1353 cells. In order to investigate the effect of puerarin on cell viability, human chondrosarcoma SW1353 cells were treated with various concentrations of puerarin $(0-300 \mu \mathrm{M})$ for $48 \mathrm{~h}$. Puerarin significantly reduced cell viability in a dose-dependent manner $(\mathrm{P}<0.05, \mathrm{P}<0.01$ and $\mathrm{P}<0.001$ compared with untreated control for 200,250 and $300 \mu \mathrm{M}$, respectively; Fig. 1A and Table I). After $48 \mathrm{~h}$ incubation, the half-maximal inhibitory concentration value of puerarin against SW1353 cells was $180.738 \mu \mathrm{M}$. Treatment of SW1353 cells for different durations indicated that puerarin treatment significantly decreases cell viability in a time-dependent manner $(\mathrm{P}<0.05, \mathrm{P}<0.01$ and $\mathrm{P}<0.001$ compared with untreated control for 48, 60 and 72 h, respectively; Fig. 1B).

Puerarin induces apoptosis in SW1353 cells. To observe the effect of puerarin on cell apoptosis, flow cytometric analysis was conducted. Puerarin treatment (48 h) significantly increased the rate of apoptosis of SW1353 cells in a dose-dependent manner $(\mathrm{P}<0.05, \mathrm{P}<0.01$ and $\mathrm{P}<0.001$ compared with the untreated control for 150, 200 and $250 \mu \mathrm{M}$, respectively; Fig. 2A and B). Puerarin exposure increased the apoptosis rate of SW1353 cells to $38.28 \%$ with a dose of $200 \mu \mathrm{M}$. 
A

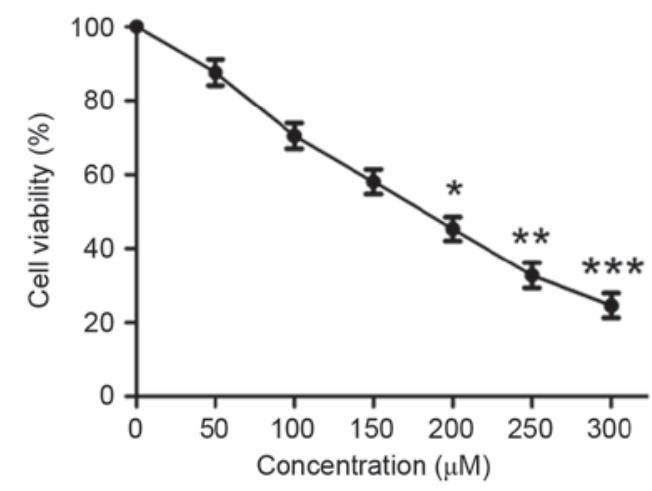

B

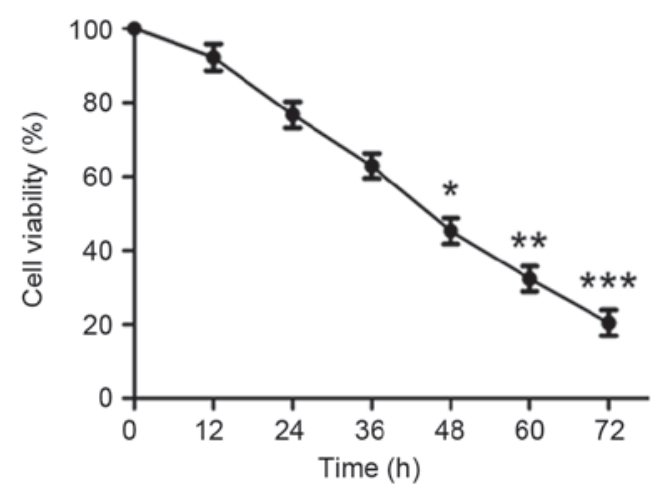

Figure 1. Anti-proliferative effect of puerarin on human chondrosarcoma SW1353 cells in vitro. (A) SW1353 cells were treated with various concentrations of puerarin $(0-300 \mu \mathrm{M})$ for $48 \mathrm{~h}$. (B) SW1353 cells were incubated with the indicated concentration of puerarin (200 $\mu \mathrm{M})$ for various periods of time. Cell viability was determined by MTT assay. Data are presented as the mean \pm standard deviation from four separate experiments. ${ }^{*} \mathrm{P}<0.05$, ${ }^{* *} \mathrm{P}<0.01$ and ${ }^{* * *} \mathrm{P}<0.001$, comparison with the untreated control.

A

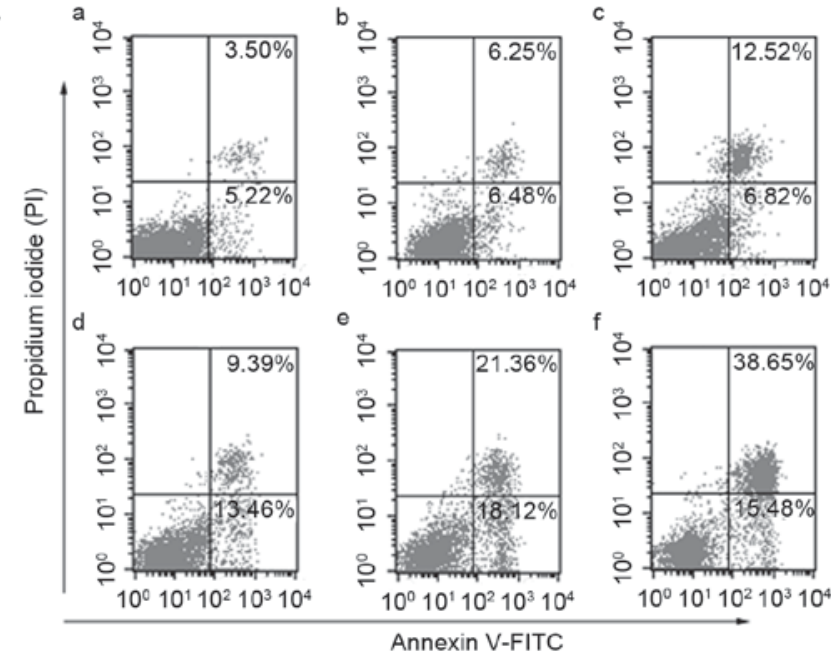

B

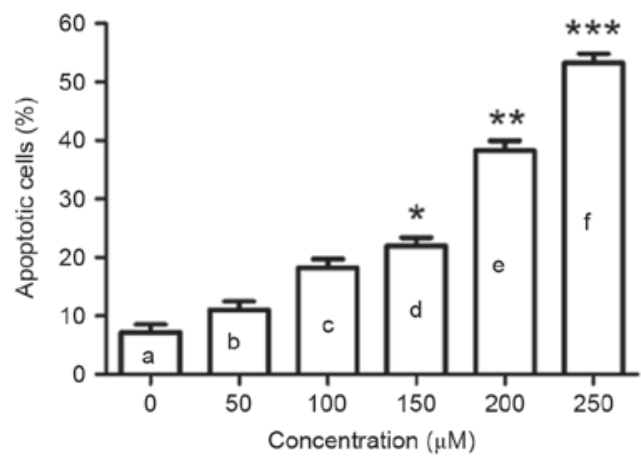

Figure 2. Flow cytometric analysis of apoptosis in SW1353 cells following puerarin treatment. (A) SW1353 cells were treated with different concentrations of puerarin [(a) $0 \mu \mathrm{M}$, (b) $50 \mu \mathrm{M}$, (c) $100 \mu \mathrm{M}$, (d) $150 \mu \mathrm{M}$, (e) $200 \mu \mathrm{M}$, (f) $250 \mu \mathrm{M}$ ) for $48 \mathrm{~h}$. A flow cytometry assay was performed to determine the apoptosis rate, and apoptotic cells (Annexin $\mathrm{V}^{+} \mathrm{PI}-$ and Annexin $\mathrm{V}^{+} \mathrm{PI}^{+}$) are presented. (B) Percentage of apoptotic cells. Data are presented as the mean \pm standard deviation $(\mathrm{n}=4) .{ }^{*} \mathrm{P}<0.05,{ }^{* *} \mathrm{P}<0.01$ and ${ }^{* * *} \mathrm{P}<0.001$, compared with the untreated control. PI, propidium iodide; FITC, fluorescein isothiocyanate.

Puerarin accelerates enzymatic activity of caspase-3 and caspase-9. Next, the effect of puerarin on the enzymatic activity of caspase- 3 and -9 was investigated. The enzymatic activity of caspase-3, an important marker of apoptosis (12), was significantly increased in SW1353 cells following puerarin stimulation in a dose-dependent manner $(\mathrm{P}<0.05$, $\mathrm{P}<0.01$ and $\mathrm{P}<0.001$ compared with the untreated control for 150,200 and $250 \mu \mathrm{M}$, respectively; Fig. 3A). Additionally, the enzymatic activity of caspase-9 in was significantly increased in a dose-dependent manner $(\mathrm{P}<0.05, \mathrm{P}<0.05$ and $\mathrm{P}<0.01$ compared with the untreated control for 150,200 and $250 \mu \mathrm{M}$, respectively; Fig. 3B).

Effect of puerarin on the expression of apoptosis-associated protein in SW1353 cells. Next, the effect of puerarin on the expression of apoptosis-associated proteins was investigated. In line with the Annexin V-FITC/PI staining results, puerarin treatment significantly increased the ratio of $\mathrm{Bax} / \mathrm{Bcl}-2$ compared with the untreated control $(\mathrm{P}<0.01, \mathrm{P}<0.01, \mathrm{P}<0.001$ and $\mathrm{P}<0.001$ for 100 ,
150, 200 and $250 \mu \mathrm{M}$, respectively; Fig. 4A and B). In addition, exposure of SW1353 cells to puerarin significantly increased the expression of cleaved caspase- 3 in a dose-dependent manner compared with the untreated control $(\mathrm{P}<0.05, \mathrm{P}<0.01, \mathrm{P}<0.001$ and $\mathrm{P}<0.001$ for 100, 150, 200 and $250 \mu \mathrm{M}$, respectively; Fig. 4A and $\mathrm{B})$. The $\mathrm{Bax} / \mathrm{Bcl} 2$ ratio and expression of cleaved caspase- 3 increased $\sim 20$ and $\sim$-fold following treatment with $200 \mu \mathrm{M}$ puerarin, respectively (Fig. 4B).

Puerarin suppresses the P13K/Akt signaling pathway in SW1353 cells. Changes in the P13K/Akt signaling pathway were analyzed by western blotting in order to determine the underlying molecular mechanisms of the effect of puerarin on SW1353 cells. The expression level of p-Akt (Ser473), in addition to the ratio of p-Akt/Akt was significantly decreased in response to puerarin treatment compared with the untreated control $(\mathrm{P}<0.05, \mathrm{P}<0.01, \mathrm{P}<0.001$ and $\mathrm{P}<0.001$ for $100,150,200$, $250 \mu \mathrm{M}$, respectively; Fig. 5A); however, the P13K inhibitor LY294002 significantly abrogated this effect (Fig. 5B). 
A

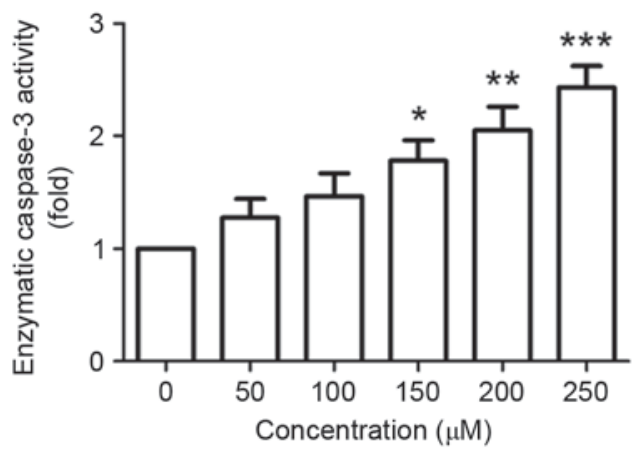

B

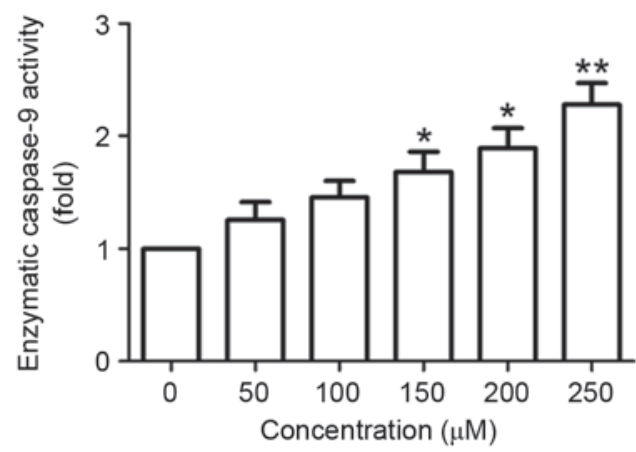

Figure 3. Effect of puerarin on the enzymatic activity of caspase-3 and caspase-9. SW1353 cells were treated with different concentrations of puerarin $(0-300 \mu \mathrm{M})$ for $48 \mathrm{~h}$. Enzymatic assay for (A) caspase-3 activity and (B) caspase- 9 activity was analyzed. Data are presented as the mean \pm standard deviation $(\mathrm{n}=4) .{ }^{*} \mathrm{P}<0.05,{ }^{* *} \mathrm{P}<0.01$ and ${ }^{* * *} \mathrm{P}<0.001$, comparison with the untreated control.

A

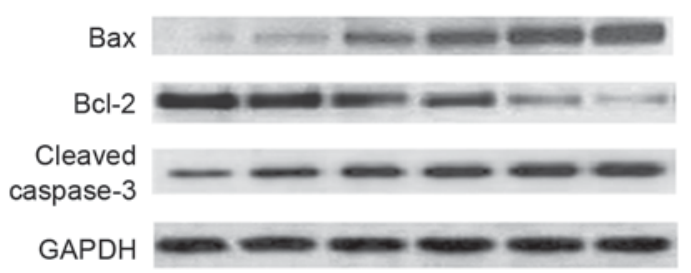

B

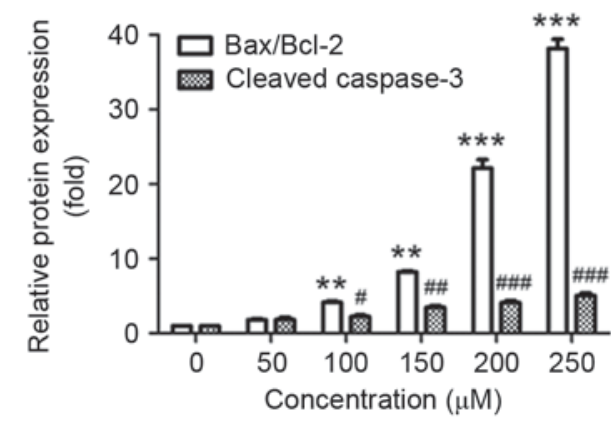

Figure 4. Puerarin regulates the expression of apoptosis-associated proteins in SW1353 cells. (A) Protein expression of Bax, Bcl-2 and cleaved caspase-3 in SW1353 cells treated with different concentrations of puerarin $(0-300 \mu \mathrm{M})$ for $48 \mathrm{~h}$. (B) The relative protein expression was quantified and assessed. Data are presented as the mean \pm standard deviation $(\mathrm{n}=4) .{ }^{* *} \mathrm{P}<0.05$ and ${ }^{* * * *} \mathrm{P}<0.001$ compared with the untreated control; ${ }^{\#} \mathrm{P}<0.05,{ }^{\# \#} \mathrm{P}<0.01$ and ${ }^{\# \# \#} \mathrm{P}<0.001$, compared with the untreated control. Bcl-2, B-cell lymphoma 2; Bax, Bcl-2-associated X protein.

Next, SW1353 cells were treated with different signaling inhibitors, including LY294002, PD98059, SP600125 and SB203580 prior to treatment with puerarin. Notably, LY294002 abrogated the enzymatic activity of caspase- 3 promoted by puerarin, but not the extracellular signal-regulated kinase inhibitor (PD98059), p38 mitogen-activated protein kinase inhibitor (SB203580) or c-Jun N-terminal kinase inhibitor (SP600125) (Fig. 6).

\section{Discussion}

Puerarin exhibits a variety of biological effects, including anti-oxidant, anti-inflammatory and anti-apoptotic activities (13). In the present study, the antitumor activity of puerarin against human chondrosarcoma was investigated, in addition to its possible mechanisms of action, using SW1353 cells. The results indicated that puerarin treatment induced apoptosis in SW1353 cells via inhibition of the P13K/Akt signaling pathway.

Previous studies have demonstrated that puerarin exerts protective biological effects by suppressing cell apoptosis; puerarin treatment blocked cell apoptosis induced by $\mathrm{H}_{2} \mathrm{O}_{2}$ in $\mathrm{PC} 12$ cells, which was associated with a reduction in c-Myc expression, an increase in the Bcl-2/Bax ratio and the inhibition of caspase-3 activation (14). Another study reported that puerarin exhibited a protective effect against the lipopolysaccharide (LPS)-induced apoptosis of H9c2 cardiomyocytes by reversing LPS-induced downregulation of Bax and upregulation of Bcl-2 (15). In addition, puerarin afforded protection against beta-amyloid-induced neurotoxicity by inhibiting apoptosis in PC12 cells, which contributed to activation of the PI3K-dependent signaling pathway in association with Akt phosphorylation (16). Although anti-apoptotic mechanisms have been demonstrated to be involved in the protective effect of puerarin in the nervous and cardiovascular system $(17,18)$, in the present study, puerarin demonstrated antitumor effects by reducing cell viability and inducing cell apoptosis in SW1353 cells, which may be important for the clinical treatment of patients with cancer.

In colon cancer HT-29 cells, puerarin treatment regulated the expression of apoptosis-associated proteins, including Bax, Bcl-2 and caspase-3 (5). A previous study demonstrated that the antitumor activity of puerarin 6'-O-xyloside on the human lung carcinoma A549 cell line, which was one of the major isoflavones of Porites lobata. The mechanisms were associated with increased levels of caspase-3, caspase-7, caspase-9 and Bax, and decreased levels of Bcl-2 (19). Combined with or without 5-fluorouracil, puerarin induced significant proliferation suppression and apoptosis in Eca-109 esophageal cancer cells in vitro and in vivo (20). In addition, puerarin inhibited 

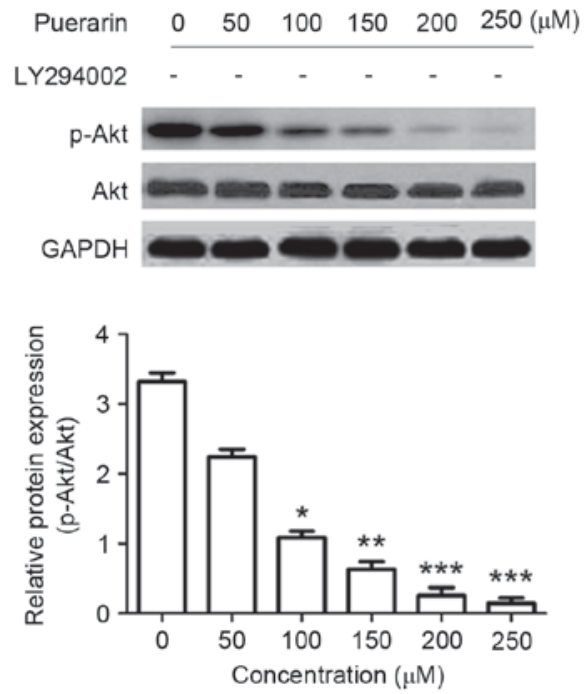

B
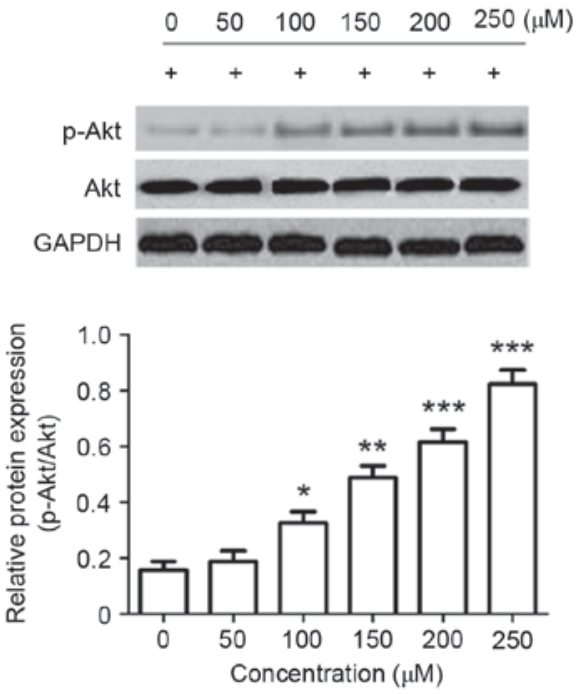

Figure 5. Effect of puerarin on the expression of p-Akt (Ser473) in SW1353 cells. SW1353 cells were treated with different concentrations of puerarin $(0-300 \mu \mathrm{M})$ for $48 \mathrm{~h}$. Protein expression of p-Akt and Akt were detected in the (A) presence or (B) absence of the phosphoinositide 3-kinase inhibitor LY294002. The relative protein expression was quantified and assessed, respectively. A representative blot is presented for each experiment. Data are presented as the mean \pm standard deviation $(\mathrm{n}=4) .{ }^{*} \mathrm{P}<0.05,{ }^{* *} \mathrm{P}<0.01$ and ${ }^{* * *} \mathrm{P}<0.001$, compared with the untreated control. Akt, RAC-alpha serine/threonine-protein kinase; p, phosphorylated.

A

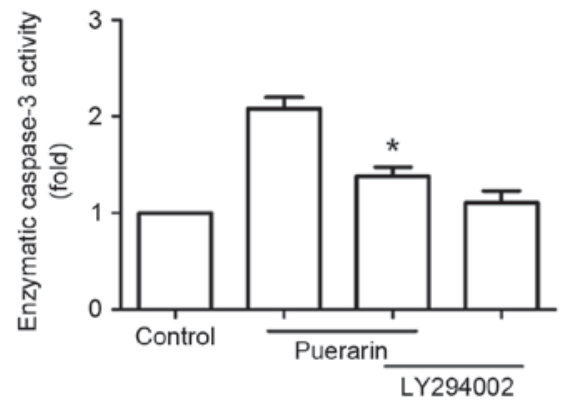

$\mathrm{C}$

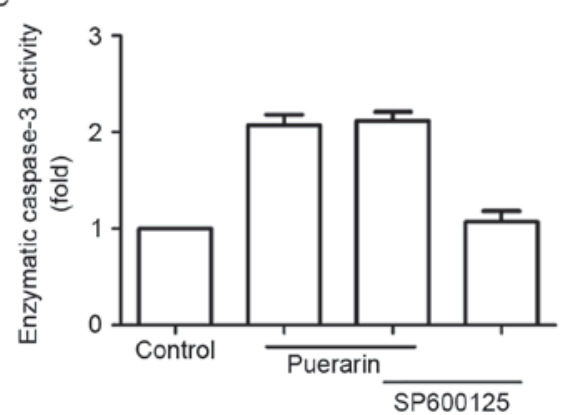

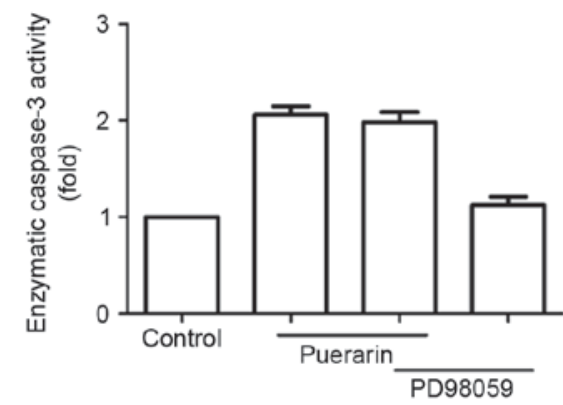

D

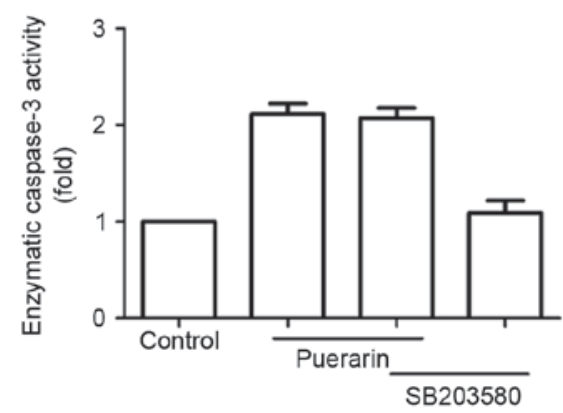

Figure 6. The phosphoinositide 3-kinase inhibitor LY294002 abolishes puerarin-induced apoptosis in SW1353 cells. SW1353 cells were pretreated with different inhibitors including (A) LY294002, (B) PD98059, (C) SP600125 and (D) SB203580 for $1 \mathrm{~h}$ prior to puerarin treatment (200 $\mu$ M), respectively. Following $48 \mathrm{~h}$ incubation, the enzymatic assay for caspase-3 activity was analyzed. Data are presented as the mean \pm standard deviation ( $\mathrm{n}=4$ ). ${ }^{*} \mathrm{P}<0.05$, compared with the puerarin-only-treated group.

proliferation and induced apoptosis in U251 and U87 human glioblastoma cell lines, and cell cycle arrest and DNA damage may participate in the anticancer effects of puerarin (7). In SMMC-7721 hepatocellular carcinoma cells, puerarin suppressed cell viability and induced cell apoptosis (21). In human breast cancer cell lines HS578T, MDA-MB-231 and MCF-7, Puerariae radix isoflavones and their metabolites reduced cell growth and induced cell apoptosis, suggesting that puerariae may act as a chemotherapeutic agent against breast cancer (9). In keeping with previous reports, the present study demonstrated that puerarin significantly inhibits the proliferation of SW1353 cells in a time- and dose-dependent manner. Additionally, the percentage of apoptotic cells and expression of apoptosis-associated proteins were increased following 
puerarin treatment, suggesting that induction of apoptosis may be the primary mechanism of the anti-proliferative effect of puerarin in SW1353 cells.

Apoptosis, also known as programmed cell death, is characterized by two classical pathways: The death receptor pathway and the mitochondrial pathway (22). Caspase-9 is the initiating protein in the caspase cascade, and caspase-3, a biomarker for cell apoptosis, is activated by caspase-9 (23). In addition, Bax and $\mathrm{Bcl}-2$ are involved in the apoptotic process as pro-apoptotic protein and anti-apoptotic proteins, respectively (24). The results of the present study confirmed that apoptosis-associated mechanisms participated in the suppressive effect of puerarin. In the present study, puerarin significantly elevated the enzymatic activity of caspase- 3 and caspase-9. Furthermore, puerarin treatment increased the $\mathrm{Bax} / \mathrm{Bcl}-2$ ratio and promoted the expression of caspase-3 in SW1353 cells.

The molecular mechanisms underlying the effects of puerarin pharmacological activities are complex, and different studies led to different conclusions. A previous study demonstrated that puerarin protected pancreatic $\beta$-cell survival via the P13K/Akt signaling pathway (25). Neuroprotective effects of puerarin against beta-amyloid-induced neurotoxicity in PC12 cells were associated with activation of the PI3K-dependent signaling pathway (26). Puerarin retarded the progression of cardiac hypertrophy and apoptosis, which may be mediated by blockade of the P13K/Akt and JNK signaling pathways (27). Conversely, puerarin demonstrated anti-proliferative and pro-apoptotic effects by inhibiting the P13K/Akt/nuclear factor $\kappa$-B cells pathway in human mantle cell lines Z138 (6). In line with this report, the results from the present study indicated that puerarin inhibits activation of p-Akt, which was abrogated by the P13K inhibitor LY294002, suggesting that the P13K/Akt signaling pathway is involved in the anticancer effect of puerarin. These differences observed in the effects of puerarin may be attributed to different doses and treatment times of puerarin used in different animal and cell models. Another reason may be that these signaling pathways connect with each other to form networks (28), therefore they may be influenced by each other.

In conclusion, the present study demonstrated that puerarin treatment induced apoptosis in SW1353 cells via inhibition of the P13K/Akt signaling pathway, which resulted in increased expression of caspase- 3 and a decreased Bcl-2/Bax ratio. These findings suggested that puerarin may be a potential option as a therapeutic drug for patients with chondrosarcoma.

\section{References}

1. Leddy LR and Holmes RE: Chondrosarcoma of bone. Cancer Treat Res 162: 117-130, 2014

2. Outani H, Hamada K, Imura Y, Oshima K, Sotobori T, Demizu Y, Kakunaga S, Joyama S, Imai R, Okimoto T, et al: Comparison of clinical and functional outcome between surgical treatment and carbon ion radiotherapy for pelvic chondrosarcoma. Int J Clin Oncol 21: 186-193, 2016.

3. Isakoff MS, Bielack SS, Meltzer P and Gorlick R: Osteosarcoma: Current treatment and a collaborative pathway to success. J Clin Oncol 33: 3029-3035, 2015.

4. Maji AK, Pandit S, Banerji P and Banerjee D: Pueraria tuberosa: A review on its phytochemical and therapeutic potential. Nat Prod Res 28: 2111-2127, 2014.

5. $\mathrm{Yu} \mathrm{Z}$ and $\mathrm{Li} \mathrm{W}$ : Induction of apoptosis by puerarin in colon cancer HT-29 cells. Cancer Lett 238: 53-60, 2006.

6. Gan M and Yin X: Puerarin induced in mantle cell lymphoma apoptosis and its possible mechanisms involving multi-signaling pathway. Cell Biochem Biophys 71: 367-373, 2015.
7. Yang JA, Li JQ, Shao LM, Yang Q, Liu BH, Wu TF, Wu P, Yi W and Chen QX: Puerarin inhibits proliferation and induces apoptosis in human glioblastoma cell lines. Int J Clin Exp Med 8: 10132-10142, 2015.

8. Yanagihara K, Ito A, Toge T and Numoto M: Antiproliferative effects of isoflavones on human cancer cell lines established from the gastrointestinal tract. Cancer Res 53: 5815-5821, 1993.

9. Lin YJ, Hou YC, Lin CH, Hsu YA, Sheu JJ, Lai CH, Chen BH, Lee Chao PD, Wan L and Tsai FJ: Puerariae radix isoflavones and their metabolites inhibit growth and induce apoptosis in breast cancer cells. Biochem Biophys Res Commun 378: 683-688, 2009

10. Yu D, Mu S, Zhao D, Wang G, Chen Z, Ren H and Fu Q: Puerarin attenuates glucocorticoid-induced apoptosis of hFOB1.19 cells through the JNK- and Akt-mediated mitochondrial apoptotic pathways. Int J Mol Med 36: 345-354, 2015.

11. Wang Y, Wang WL, Xie WL, Li LZ, Sun J, Sun WJ and Gong HY: Puerarin stimulates proliferation and differentiation and protects against cell death in human osteoblastic MG-63 cells via ER-dependent MEK/ERK and PI3K/Akt activation. Phytomedicine 20: 787-796, 2013.

12. Konstantinidou AE, Givalos N, Gakiopoulou H, Korkolopoulou P, Kotsiakis X, Boviatsis E, Agrogiannis G, Mahera H and Patsouris E: Caspase-3 immunohistochemical expression is a marker of apoptosis, increased grade and early recurrence in intracranial meningiomas. Apoptosis 12: 695-705, 2007.

13. Zhou YX, Zhang $\mathrm{H}$ and Peng C: Puerarin: A review of pharmacological effects. Phytother Res 28: 961-975, 2014.

14. Jiang B, Liu JH, Bao YM and An LJ: Hydrogen peroxide-induced apoptosis in pc1 2 cells and the protective effect of puerarin. Cell Biol Int 27: 1025-1031, 2003.

15. Yuan Y, Zhou H, Wu QQ, Li FF, Bian ZY, Deng W, Zhou MQ and Tang QZ: Puerarin attenuates the inflammatory response and apoptosis in LPS-stimulated cardiomyocytes. Exp Ther Med 11: 415-420, 2016

16. Zhang HY, Liu YH, Wang HQ, Xu JH and Hu HT: Puerarin protects PC12 cells against beta-amyloid-induced cell injury. Cell Biol Int 32: 1230-1237, 2008

17. Wang G, Zhou L, Zhang Y, Dong M, Li X, Liu J and Niu Y: Implication of the c-Jun-NH2-terminal kinase pathway in the neuroprotective effect of puerarin against 1-methyl-4-phenylpyridinium (MPP+)-induced apoptosis in PC-12 cells. Neurosci Lett 487: 88-93, 2011.

18. Yuan Y, Zong J, Zhou H, Bian ZY, Deng W, Dai J, Gan HW, Yang Z, Li H and Tang QZ: Puerarin attenuates pressure overload-induced cardiac hypertrophy. J Cardiol 63: 73-81, 2014.

19. Chen T, Chen H, Wang $Y$ and Zhang J: In vitro and in vivo antitumour activities of puerarin 6'-O-xyloside on human lung carcinoma A549 cell line via the induction of the mitochondria-mediated apoptosis pathway. Pharm Biol 54: 1793-1799, 2016

20. Wang J, Yang ZR, Guo XF, Song J, Zhang JX, Wang J and Dong WG: Synergistic effects of puerarin combined with 5-fluorouracil on esophageal cancer. Mol Med Rep 10: 2535-2541, 2014

21. Zhang WG, Liu XF, Meng KW and Hu SY: Puerarin inhibits growth and induces apoptosis in SMMC-7721 hepatocellular carcinoma cells. Mol Med Rep 10: 2752-2758, 2014.

22. Ouyang L, Shi Z, Zhao S, Wang FT, Zhou TT, Liu B and Bao JK: Programmed cell death pathways in cancer: A review of apoptosis, autophagy and programmed necrosis. Cell Prolif 45: 487-498, 2012.

23. Blanc C, Deveraux QL, Krajewski S, Jänicke RU, Porter AG, Reed JC, Jaggi R and Marti A: Caspase-3 is essential for procaspase-9 processing and cisplatin-induced apoptosis of MCF-7 breast cancer cells. Cancer Res 60: 4386-4390, 2000.

24. Zheng TS, Hunot S, Kuida K, Momoi T, Srinivasan A, Nicholson DW, Lazebnik Y and Flavell RA: Deficiency in caspase-9 or caspase-3 induces compensatory caspase activation. Nat Med 6: 1241-1247, 2000.

25. Li Z, Shangguan Z, Liu Y, Wang J, Li X, Yang S and Liu S: Puerarin protects pancreatic $\beta$-cell survival via PI3K/Akt signaling pathway. J Mol Endocrinol 53: 71-79, 2014.

26. Xing G, Dong M, Li X, Zou Y, Fan L, Wang X, Cai D, Li C, Zhou L, Liu J and Niu Y: Neuroprotective effects of puerarin against beta-amyloid-induced neurotoxicity in PC12 cells via a PI3K-dependent signaling pathway. Brain Res Bull 85: 212-218, 2011.

27. Yuan Y, Zong J, Zhou H, Bian ZY, Deng W, Dai J, Gan HW, Yang Z, Li H and Tang QZ: Puerarin attenuates pressure overload-induced cardiac hypertrophy. J Cardiol 63: 73-81, 2014.

28. Lavrik IN: Systems biology of apoptosis signaling networks. Curr Opin Biotechnol 21: 551-555, 2010. 